\title{
Coamorphous Atorvastatin Calcium to Improve its Physicochemical and Pharmacokinetic Properties
}

\author{
Ali Shayanfar ${ }^{1,2}$, Hamed Ghavimi ${ }^{3}$, Hamed Hamishehkar ${ }^{4}$, Abolghasem Jouyban $^{1,4}$ \\ ${ }^{1}$ Faculty of Pharmacy, ${ }^{2}$ Students' Research Committee, ${ }^{3}$ Liver and Gastrointestinal Diseases Research Center and ${ }^{4}$ Drug \\ Applied Research Center, Tabriz University of Medical Sciences, Tabriz, Iran
}

Received, May 05, 2013; Revised, July 1, 2013 Accepted, September 15, 2013; Published, September 18, 2013.

\begin{abstract}
Purpose: Atorvastatin calcium (ATC) is classified as class II (low solubility and high permeability) compound according to the biopharmaceutical classification system. The amorphous form of ATC possesses higher solubility, dissolution rate, and bioavailability than its crystalline form. Coamorphous drug system is a new and emerging method to prepare stable amorphous forms, in this case leading to the improved stability of ATC in dissolution medium. Methods: In this study, coamorphous form of ATC and nicotinamide (ATC-NIC) was prepared from solvent evaporation method and characterized using differential scanning calorimetry (DSC), Fourier transform infrared spectroscopy (FT-IR) and powder X-ray diffraction (PXRD). The intrinsic dissolution rate and solubility of ATC-NIC were determined along with plasma concentrations of ATC using HPLC after oral dosing in rats. Results: The crystalline ATC was converted to coamorphous form revealing a molecular interaction between ATC and NIC. The intrinsic dissolution rate, solubility and plasma concentration of coamorphous ATC-NIC are higher than those of crystalline ATC. ATC-NIC coamorphous system showed greater solution stability than those reported in the literature for amorphous ATC. Conclusions: Coamorphous ATC-NIC has improved physicochemical and pharmacokinetic properties as compared to ATC.
\end{abstract}

This article is open to POST-PUBLICATION REVIEW. Registered readers (see "For Readers") may comment by clicking on ABSTRACT on the issue's contents page.

\section{INTRODUCTION}

More than $75 \%$ of drug candidates and $40 \%$ of the marketed drugs are poorly soluble in water, hence, have limited absorption and bioavailability (1-2). Amidon and co-workers classified drugs into four main groups according to their permeability and solubility, commonly known as the biopharmaceutical classification system (BCS). According to the BCS, ATC falls into Class II (3), i.e., low solubility and high permeability (4). There are different methods used to improve dissolution rate and solubility of class II drugs $(1,5)$. Crystal engineering strategies are applied to modify the physicochemical properties of drugs. This is commonly achieved via salt formation when feasible, polymorphs, solvate (or hydrate), amorphous forms and more recently, cocrystal and coamorphous systems $(6,7)$.

Although amorphous systems are a useful way of improving solubility and dissolution rate, they are thermodynamically unstable and will crystallize over pharmaceutically relevant time scales, i.e. different physical conditions (physical stability) and solubility or dissolution experiments (solution stability). Solution stability is a critical issue for solutions, suspensions and for solid dosage forms that will dissolve in the gastrointestinal tract (8) because of possible conversion of amorphous to crystalline forms attributed to a strong driving force for crystallization in the dissolution media (1). Excipients such as polymers can be used to stabilize amorphous systems. Solid polymer dispersions are applied to enhance solubility and dissolution rate of drugs $(1,5,9)$. However, these systems tend to be hygroscopic in nature. The absorbed moisture leads to lowering of the glass transition temperature $\left(\mathrm{T}_{\mathrm{g}}\right)$, resulting in phase separation and recrystallization. In addition, in some cases, large quantities of polymers are required for solid dispersions which it is caused difficulties in manufacturing and processing (10).

Corresponding Author: Prof. A. Jouyban, Faculty of Pharmacy, Tabriz University of Medical Sciences, Tabriz, Iran, Email: ajouyban@hotmail.com 
Alternative methods to stablize amorphous systems, such as mesoporous materials and binary Coamorphous mixtures (10) have recently been investigated. Amorphous small molecule mixtures (coamorphous or amorphous cocrystals) is an example of one such recent method developed to produce amorphous drugs in the presence of a second compound which could either be another active pharmaceutical agent or an excipient, resulting in improved stability (10). Cimitidineindomethacin (11), ranitidine hydrochlorideindomethacin (12), simvastatin-glipizide (13), cimetidine-diflunisal (14), acyclovir-citric acid (15), naproxen-cimetidine (16) and indomethacinnaproxen (17) are examples of coamorphous systems from the literature.

Statins are a class of cholesterol lowering drugs which have low dissolution rate and bioavailability, warranting the preparation of novel formulations (18). Atorvastatin calcium (ATC), one of the world's top-selling, has an absolute oral bioavailability of $12 \%(\% \mathrm{~F})$ from an oral dosage form. In addition, solubilization of ATC is necessary to produce novel formulations of ATC (18).

There are 42 crystalline forms of ATC (19) and the amorphous form possesses higher solubility and dissolution rate than crystalline forms $(20,21)$. The amorphous ATC form was prepared using different methods, such as antisolvent precipitation, pulverization, spray drying, melt quenching, supercritical antisolvent process and other various methods (20-23). These reported methods are complex and time-consuming, and exact method details have not been reported in the registered patents $(22,23)$.

In this study, coamorphous form of ATC with nicotinamide (ATC-NIC), a pharmaceutically acceptable coformer (24), were prepared in order to improve physicochemical properties, i.e. powder dissolution rate, intrinsic dissolution rate and solubility of ATC in coamorphous form. In addition, intestinal absorption rate of the prepared coamorphous form was evaluated with in vivo rat studies. The plasma concentrations from the in-life portion of this study were determined by a modified HPLC.

\section{METHODS}

\section{Materials}

ATC from Novin Kavosh Mamtir Co. (Tehran, Iran), NIC from Zahravi pharmaceutical Co.
(Tabriz, Iran), trifluoroacetic acid and sodium lauryl sulfate (SLS) (99\%) from Merck (Darmstadt, Germany), methanol (99\%), acetonitrile (99\%) were purchased from Scharlau Chemie (Barcelona, Spain) and ethanol (96\%) for dilution of solutions was provided form Jahan Alcohol Teb (Arak, Iran), respectively. Distilled water for the preparation of the solutions and deionized water from Shahid Ghazi pharmaceutical Co. (Tabriz, Iran) for HPLC analysis were used.

\section{Preparation of coamorphous ATC-NIC}

The ATC-NIC coamorphous system was prepared using solvent evaporation. Briefly, 1:1 mixture of ATC $(0.1 \mathrm{mmol})$ and NIC $(0.1 \mathrm{mmol})$ were dissolved in $10 \mathrm{~mL}$ of methanol and the resulting mixture was left at $30{ }^{\circ} \mathrm{C}$ for $48 \mathrm{~h}$ in order for solvent evaporation to occur.

\section{Characterization of ATC-NIC}

The thermal properties of powders were studied using DSC (Perkin Elmer, Waltham, Massachusetts, USA). The system was calibrated using indium and zinc. $5 \mathrm{mg}$ samples were placed in a standard aluminum pan and sealed with a lid containing pinhole. Samples were analyzed at a heating rate of $10{ }^{\circ} \mathrm{C} \mathrm{min}{ }^{-1}$ from 35 to $200{ }^{\circ} \mathrm{C}$ under a constant flow of nitrogen. PXRD data was generated using a Siemens diffractometer D5000 (Munich, Germany). The X-ray diffractogram was scanned from 2 to $40^{\circ}, 2 \theta$ angle with steps of $0.05^{\circ}$. For Fourier transform-infrared spectroscopy (FT-IR) (Shimadzu, Kyoto, Japan) samples were prepared by mixing of drug with $\mathrm{KBr}$, pressed and scanned from $400-4000 \mathrm{~cm}^{-1}$ to study the possible interaction between ATC and NIC.

\section{Kinetic and thermodynamic solubility studies}

Kinetic solubility was determined according to the literature (21). Briefly, $100 \mathrm{mg}$ excess solid of ATC and ATC-NIC were placed with $200 \mathrm{~mL}$ water in a shaker-incubator equipped with a temperature controlling system (Heidolph, Schwabach, Germany) at $37 \pm 0.1{ }^{\circ} \mathrm{C}$ for $24 \mathrm{hr}$. Solutions were agitated constantly at $200 \mathrm{rpm}$. Approximately 2 $\mathrm{mL}$ of solution was withdrawn from slurry, filtered through $0.45 \mu \mathrm{m}$ filter and diluted with ethanol. Absorbances of the diluted solutions were measured at $284 \mathrm{~nm}$ using a Pharmacia Biotech Ultrospec $2000 \mathrm{UV} /$ Vis Spectrophotometer (Baie d'Urfe, Canada). This wavelength was chosen because NIC had no significant absorbance at $284 \mathrm{~nm}$, thus 
avoiding potential interfere with the readouts. Solubility of ATC and coamorphous ATC-NIC were equilibrated at $25,30,35,40{ }^{\circ} \mathrm{C}$ and thermodynamic properties of solution were computed using the modified van't Hoff equation described in a previous work (25).

\section{Powder dissolution rate}

Dissolution studies were performed according to the literature (21) using a dissolution bath (Kavosh, Tehran, Iran) equipped with a USP method II (paddle method) apparatus. Determination of particle size distribution of powders using a laser diffraction particle-size analyzer (Sald 2101, Shimadzu, Japan) confirmed no significant difference between ATC and ATC-NIC. For the dissolution studies, the equivalent of $50 \mathrm{mg}$ ATC was used employing a stirring speed of $50 \mathrm{rpm}$ and the temperature was maintained at $37 \pm 0.1{ }^{\circ} \mathrm{C}$. The solution samples were taken from 5-30 min, in 5min intervals. The dissolution medium (double distilled water) was then replaced in order to maintain sink conditions. The samples were then filtered using Chromafil ${ }^{\circledR}$ syringe filter $(0.20 \mu \mathrm{m}$, Duren, Germany) and diluted with ethanol, the absorbance was determined using UV/Vis spectrophotometer (Baie d'Urfe, Canada) at 284 $\mathrm{nm}$.

\section{Intrinsic dissolution rate (IDR)}

Intrinsic dissolution rate (IDR) is the dissolution rate of a drug in the presence of a constant surface area, this overcomes particle size and crystal habit effects on dissolution. IDR of ATC and ATC-NIC were determined using an improved Wood method $(26,27)$. The equivalent of $100 \mathrm{mg}$ of ATC was compressed and placed in molten beeswax in such a way that only the top side of the compact was intact with the solvent during the dissolution studies. IDR studies were performed in $1 \%$ SLS aqueous solution at $37 \pm 0.1{ }^{\circ} \mathrm{C}$ and $40 \mathrm{rpm}$ under sink conditions according to the literature (21).

\section{Pharmacokinetic study in rats Animal experiments}

Female Wistar rats (9-10 weeks old and weighing 220-260 g) were used in this study. They were housed to a cage under ambient laboratory temperature and humidity conditions, under a $12 \mathrm{hr}$ light-dark cycle with free access to water and chow in the vivarium of Tabriz University of Medical Sciences. All animal procedure treatments were approved by the Research Committee of the Tabriz University of Medical Sciences, according to the Guide to the Care and Use of Experimental Animal Care (Canadian Council on Animal Care guidelines, 1984). The rats were deprived of food for $18 \mathrm{hrs}$ before dosing (with free access to water) and were randomly divided into two groups with six rats in each group. ATC and ATC-NIC (equivalent to 25 $\mathrm{mgkg}^{-1}$ ATC), respectively were administered orally via standard gavage tube. Total gavage volume was approximately $2 \mathrm{~mL}$ and rats that resisted dosing were excluded from experiment. Blood samples $(0.3 \mathrm{~mL})$ were taken via the tail vein into heparinized Eppendorf after light anesthesia at 0.25 , $0.5,1,2,4,6 \mathrm{hrs}$ post oral delivery, and equivalent amount of saline solution was injected subcutaneously. In each step, blood samples were centrifuged using Tommy Seiko centrifuge (Tokyo, Japan) at $6000 \mathrm{rpm}$, for $10 \mathrm{~min}$. Plasma samples were transferred to Eppendorf tubes and stored at $20{ }^{\circ} \mathrm{C}$ until HPLC analyses.

\section{HPLC analysis}

Different methods were proposed for determination of ATC in biological fluids in the literature $(19,28$, 29). The concentrations of ATC in rat plasma samples were determined using a modified RPHPLC method developed by Altuntas and Erk (29). The plasma samples was mixed with acetonitrile in a 1:1 ratio for proteins precipitation, the supernatant was separated by centrifugation at $8000 \mathrm{rpm}$ for 5 min. Results of a previous study showed that acetonitrile is the best reagent to precipitate proteins (29). Our observations revealed that an overlap between ATC and a background plasma peak could be resolved by modifications of solvent composition and $\mathrm{pH}$ of the mobile phase. Agilent HPLC system (Agilent Technologies, Palo Alto, CA, USA) with a MZ ODS precolumn cartridge followed by Agilent $\mathrm{C}_{18}$ analytical column (Agilent Technologies, Palo Alto, CA, USA $150 \times 4.8 \mathrm{~mm}$, $3.5 \mu \mathrm{m})$. The mobile phase was composed of acetonitrile, methanol and water $(40: 35: 25, \mathrm{v} / \mathrm{v} / \mathrm{v})$ and $\mathrm{pH}$ adjusted to 3.0 with trifluoroacetic acid. The mobile phase composition and $\mathrm{pH}$ were changed and adjusted to resolve peaks of interfering compounds from plasma and ATC. The samples were injected using a $20 \mu \mathrm{L}$ loop, the isocratic flow rate of $1 \mathrm{~mL} / \mathrm{min}$ and UV/Vis detection at $245 \mathrm{~nm}$ was used according to the calibration curve using prepared standard solutions in rat plasma matrix. The calibration curve was prepared using 
appropriate amounts of ATC that were added to blank plasma. The calibration curves of interday and intraday were obtained by least-squares linear regression analysis of the height of peaks versus their concentrations. Accuracy, precision and recovery of three concentrations of ATC in rat plasma were calculated for the modified HPLC method.

\section{RESULTS}

\section{Characterization of coamorphous ATC-NIC PXRD}

Figure 1 shows the PXRDs of crystalline ATC and coamorphous ATC-NIC. The PXRD pattern of NIC that is a crystalline powder has no significant changes after dissolving and solvent evaporation in methanol. However, the crystalline form of ATC was converted to the semi-crystalline form because only two detectable peaks at $8.7^{\circ}$ and $18.3^{\circ}$ have been observed (data not shown). The PXRD patterns of synthesized coamorphous show typical halo without any diffraction peaks suggesting the formation of amorphous form.

\section{DSC}

DSC was used to confirm amorphous state of ATCNIC. The DSC thermogram of ATC shows a broad endotherm at $70-130{ }^{\circ} \mathrm{C}$ corresponding to the loss of water and a broad endotherm at $164{ }^{\circ} \mathrm{C}$, corresponding to the melting of ATC. The synthesized coamorphous ATC-NIC did not show any peaks, however it indicates a $\mathrm{T}_{\mathrm{g}}$ for this phase at $87{ }^{\circ} \mathrm{C}$ (Figure 2) which is in agreement with corresponding PXRD pattern indicating the formation of amorphous ATC.

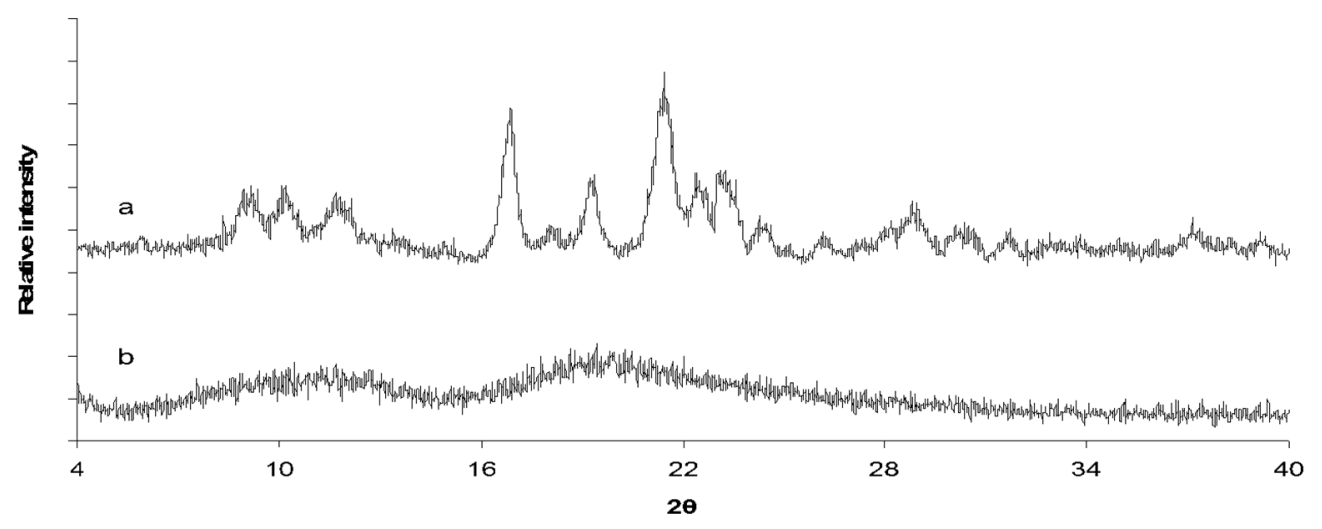

Figure 1. PXRD patterns of (a) ATC, (b) ATC-NIC

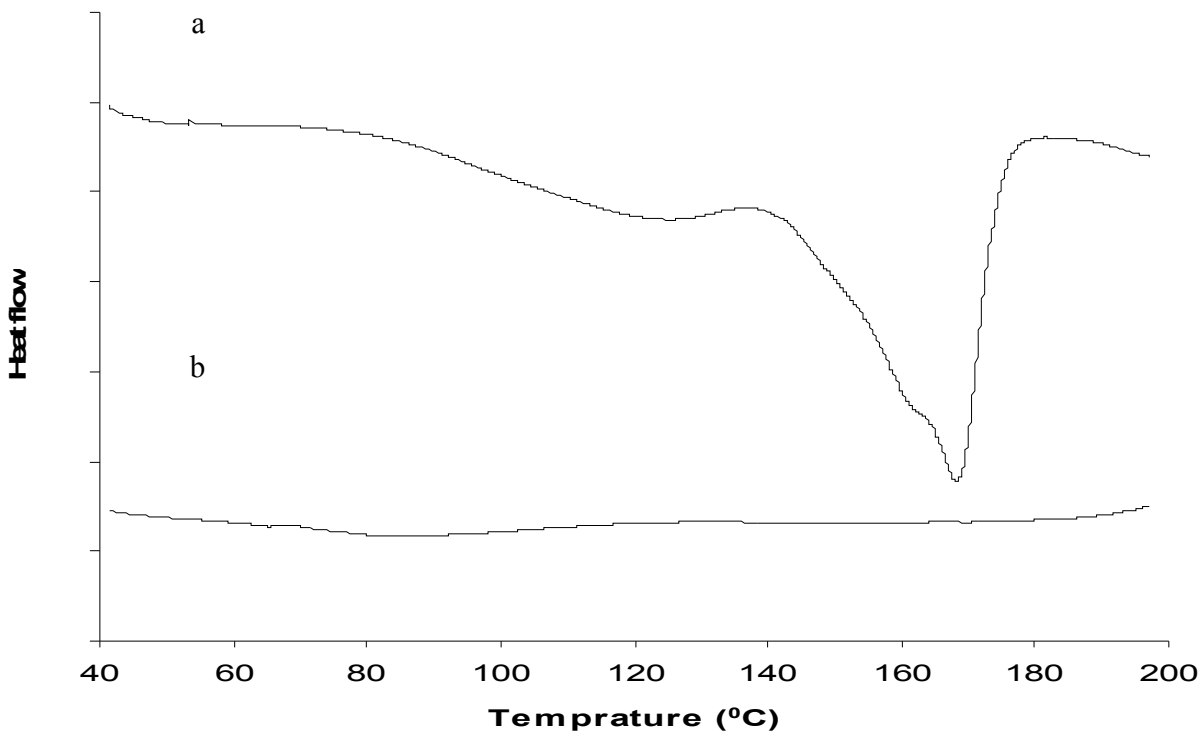

Figure 2. DSC thermograms of (a) ATC, (b) ATC-NIC 


\section{FT-IR}

FT-IR was used to confirm molecular interaction between ATC and NIC in amorphous state of ATCNIC. These spectra were exhibited in the Figure 3 illustrating significant differences in the observed vibrational transitions and the bands in the spectra.

\section{Solubility of ATC and ATC-NIC}

Figure 4 exhibits the kinetic solubility of ATC and ATC-NIC in water. This figure illustrates that solubility of coamorphous ATC-NIC is 2-fold higher than that of ATC. The coamorphous system did not show any signs of precipitation under the assay conditions after 24 hours as verified by the observed plateau in solubility seen after this period. Solubility $\left(\ln C_{T}^{\text {Sat }}\right)$ of coamorphous ATC-NIC after $24 \mathrm{hr}$ saturation in water was determined at 25 , 30,35 and $40{ }^{\circ} \mathrm{C}$ and compared to crystalline ATC solubility. Thermodynamic properties of dissolution process of a powder can be computed using solubility data at different temperatures. Dissolution enthalpy $\left(\Delta H_{d i s}\right)$, entropy $\left(\Delta S_{d i s}\right)$ and Gibbs energy $\left(\Delta G_{d i s}\right)$ changes can be calculated using the modified version of the van't Hoff equation (25):

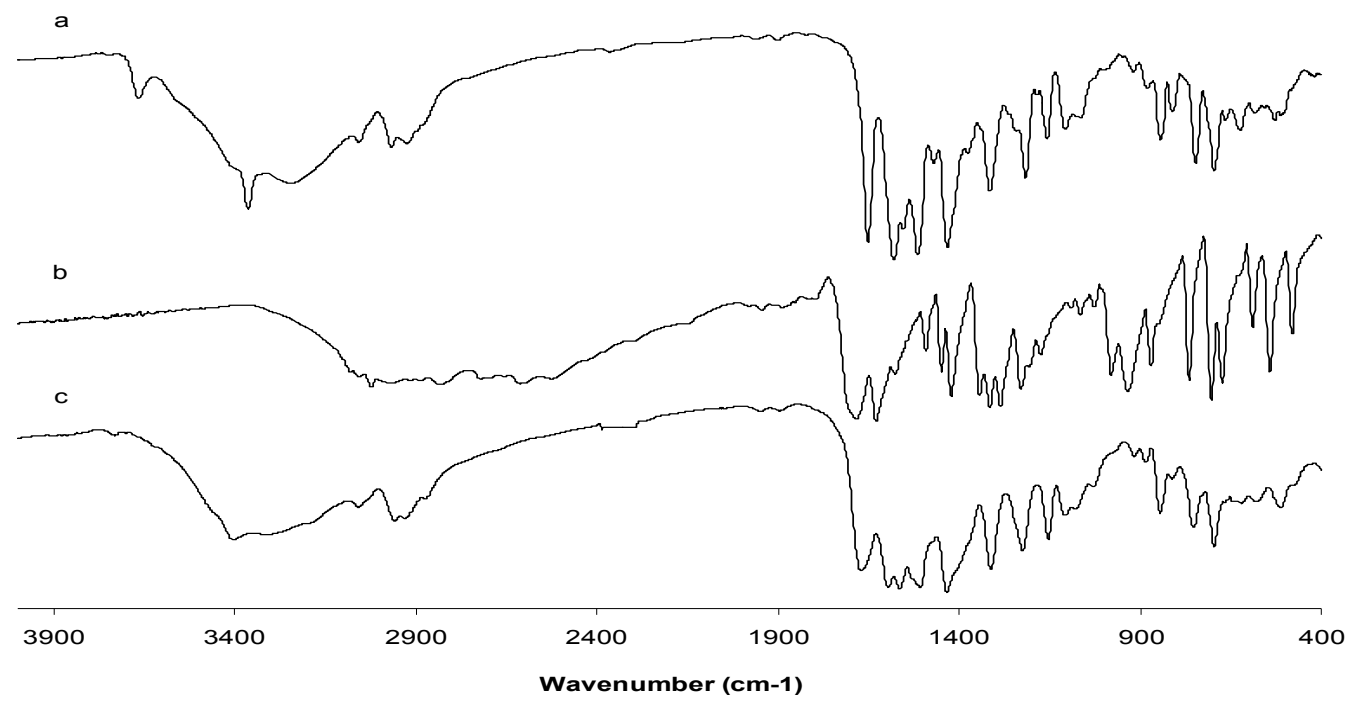

Figure 3. FTIR patterns of (a) ATC (b) NIC and (c) ATC-NIC

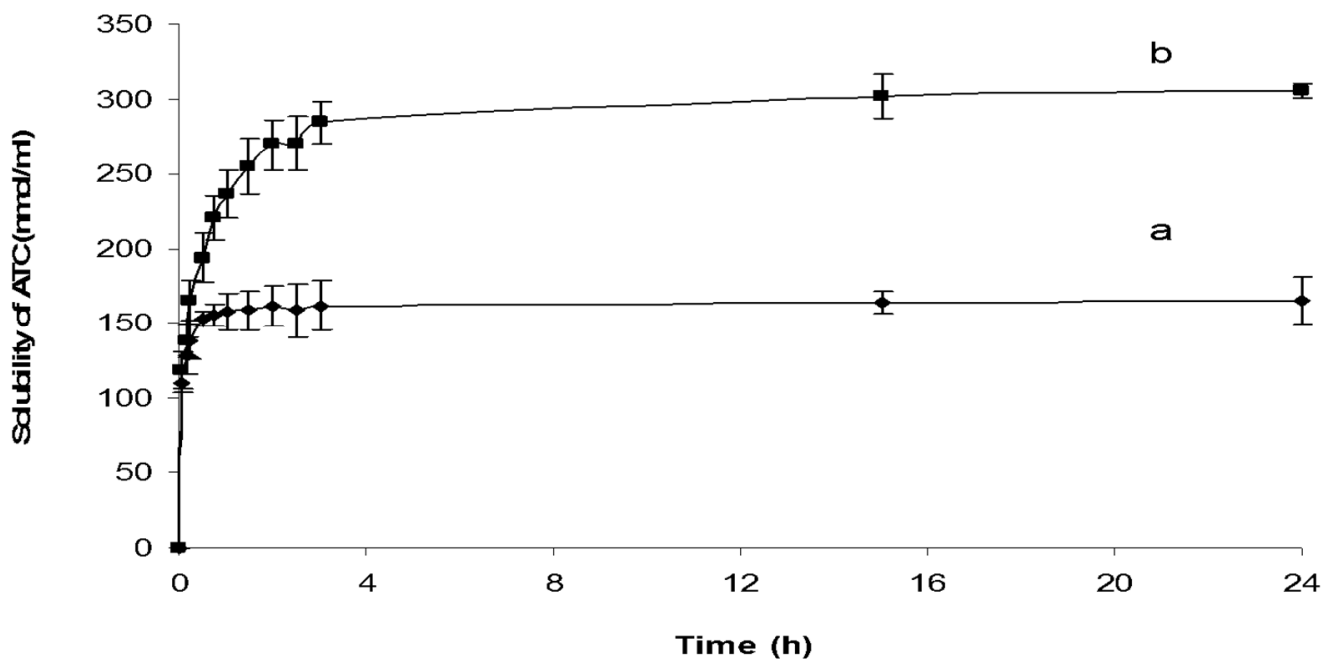

Figure 4. Kinetic solubility of (a) ATC (b) ATC-NIC in water 


$$
\ln C_{T}^{S a t}=-\frac{\Delta H}{R}\left(\frac{1}{T}-\frac{1}{T_{h m}}\right)
$$

where $R$ is the gas constant, $8.314 \mathrm{JK}^{-1} \mathrm{~mol}^{-1}$, and $\mathrm{T}_{\mathrm{hm}}$ is the mean harmonic temperature which is calculated by:

$$
T_{h m}=\frac{n}{\sum_{i=1}^{n}(1 / T)}
$$

where $n$ is the number of temperatures studied.

$$
\begin{aligned}
& \Delta G_{d i s} \text { and } \Delta S_{d i s} \text { are computed by: } \\
\Delta G_{d i s}= & -R T_{h m} \cdot \text { intercept } \\
\Delta S_{d i s}= & \frac{\Delta H_{d i s}-\Delta G_{d i s}}{T_{h m}}
\end{aligned}
$$

The relative enthalpy $\left(\% \xi_{H}\right)$ and entropic $\left(\% \xi_{T S}\right)$ contributions of the solubility of ATC in coamorphous and crystalline forms in water are computed by equations 5 and 6 , respectively:

$$
\% \xi_{H}=100 \frac{\left|\Delta H_{d i s}\right|}{\left|\Delta H_{d i s}\right|+\left|T \Delta S_{d i s}\right|}
$$

$$
\% \xi_{T S}=100 \frac{\left|T \Delta S_{d i s}\right|}{\left|\Delta H_{d i s}\right|+\left|T \Delta S_{d i s}\right|}
$$

Solubility data at different temperatures was reported in Table 1 and then thermodynamic properties, i.e. $\Delta H_{d i s}, \Delta S_{d i s}, \Delta G_{d i s} \% \xi_{H}, \% \xi_{T S}$ were computed by equations 1-6.

\section{Powder dissolution rate}

Powder dissolution profiles of ATC and physical mixture of ATC + NIC and ATC-NIC are shown in Figure 5. The dissolution rate of coamorphous ATC-NIC was significantly higher than ATC alone and a physical mixture of ATC + NIC. Approximately $90 \%$ of ATC was released after 10 min in ATC-NIC form but after the same time period, dissolution of intact ATC is less than $60 \%$.

\section{IDR}

Figure 6 shows the intrinsic dissolution rate of ATC and ATC-NIC in water containing $1 \%$ SLS. There is good linearity between time and drug

\begin{tabular}{|c|c|c|c|c|c|c|c|}
\hline $\mathbf{T}\left(\mathbf{(}^{\circ} \mathbf{C}\right)$ & $\mathrm{S}\left(\mathrm{mol} \mathrm{L}^{-1}\right)$ & $\begin{array}{l}\Delta \mathbf{H}_{\text {dis }} \\
\left(\mathbf{K J ~ m o l}^{-1}\right)\end{array}$ & $\begin{array}{l}\Delta \mathbf{G}_{\text {dis }} \\
\left(\mathbf{K J ~ m o l}^{-1} \mathbf{K}^{-1}\right)\end{array}$ & $\begin{array}{l}\Delta \mathbf{S}_{\text {dis }} \\
\left(\mathbf{J} \mathbf{~ m o l}^{-1} \mathbf{K}^{-1}\right)\end{array}$ & $\begin{array}{l}\mathbf{T} \Delta \mathbf{S}_{\mathrm{dis}} \\
\left(\mathrm{KJ} \mathrm{mol}^{-1}\right)\end{array}$ & $\% \xi_{H}$ & $\% \xi_{\mathrm{TS}}$ \\
\hline & & & ATC & & & & \\
\hline 25.0 & 0.000136 & & & & & & \\
\hline 30.0 & 0.000141 & & & & & & \\
\hline 32.5 & - & 8.30 & 22.4 & -46.2 & -14.1 & 37.0 & 63.0 \\
\hline 35.0 & 0.000148 & & & & & & \\
\hline \multirow[t]{2}{*}{40.0} & 0.000160 & & & & & & \\
\hline & & & ATC-NIC & & & & \\
\hline 25.0 & 0.000299 & & & & & & \\
\hline 30.0 & 0.000317 & & & & & & \\
\hline 32.5 & - & 6.43 & 20.4 & -46.0 & -14.0 & 31.4 & 68.6 \\
\hline 35.0 & 0.000326 & & & & & & \\
\hline 40.0 & 0.000340 & & & & & & \\
\hline
\end{tabular}
concentration $(\mathrm{R}>0.999)$ and an increase in intrinsic dissolution rate of ATC-NIC $\left(0.0261 \mathrm{nmol} \mathrm{mL}^{-1}\right.$ $\left.\mathrm{min}^{-1}\right)$ in comparison with ATC $\left(0.0194 \mathrm{nmol} \mathrm{mL}^{-1}\right.$ $\min ^{-1}$ ) is seen.

Table 1. Solubility of ATC and ATC-NIC at different temperatures and corresponding thermodynamic properties at $32.5^{\circ} \mathrm{C}$ computed by equations $1-6$ 


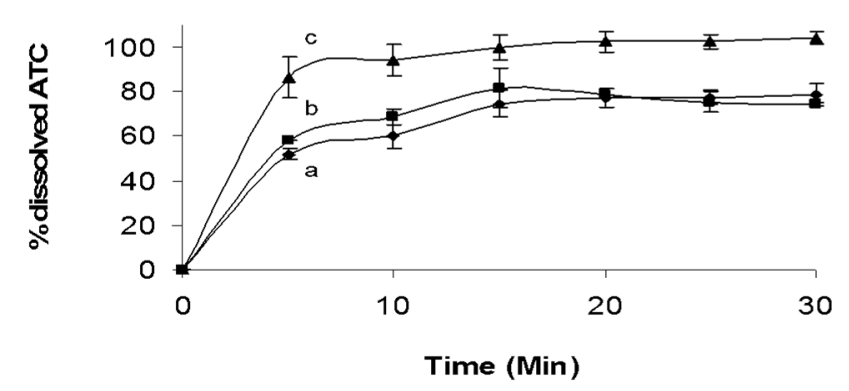

Figure 5. Powder dissolution rate of (a) ATC (b) physical mixture of ATC + NIC and (c) ATC-NIC in water at $37^{\circ} \mathrm{C}$.

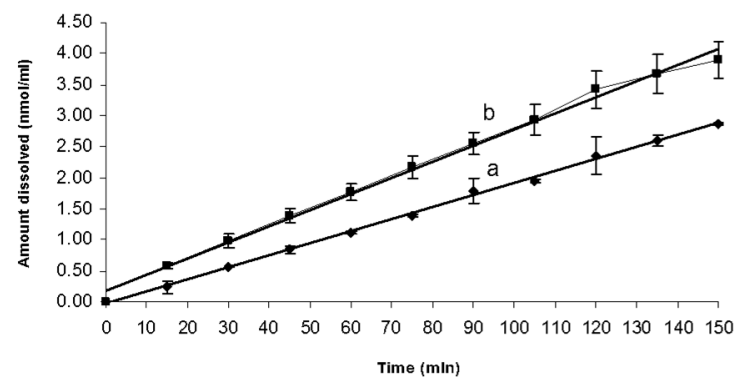

Figure 6. Intrinsic dissolution rate of (a) ATC and (b) ATC-NIC

\section{Pharmacokinetic study HPLC method}

After modification of analytical conditions, ATC peak was appeared at 2.4 min and there was no endogenous component from plasma to interfere with ATC peak (Figure 7). There was good linear relationship between concentration of ATC in plasma samples and the peak height. The limit of detection (LOD) and limit of quantification (LOQ) were approximately $53 \mathrm{ngmL}^{-1}$ and $162 \mathrm{ngmL}^{-1}$, respectively and upper limit of calibration curve was $3000 \mathrm{ngmL}^{-1}$. Precision of calibration curve were checked with intra- and inter-day variability. Accuracy data were evaluated in three different standard concentrations, which they were prepared in rat plasma and the results are summarized in Table 2. The relative standard deviation (RSD) is less than $15 \%$ for three concentration levels and the recovery is between 99 to $110 \%$, which are acceptable values according to the FDA validation criteria for plasma samples (30).

Mean plasma concentration-time profiles of ATC and ATC-NIC in rats after oral administration of $25 \mathrm{mgkg}^{-1}$ single dose, are illustrated in Figure 8. The $\mathrm{C}_{\max }$ and $\mathrm{AUC}_{0-24}$ of ATC are 419 and 46556
$\mathrm{ngmL}^{-1}$ and those for ATC-NIC are 941 and 79864 ngmL ${ }^{-1}$, respectively. These pharmacokinetic properties obviously are higher when compared with those of crystalline ATC.

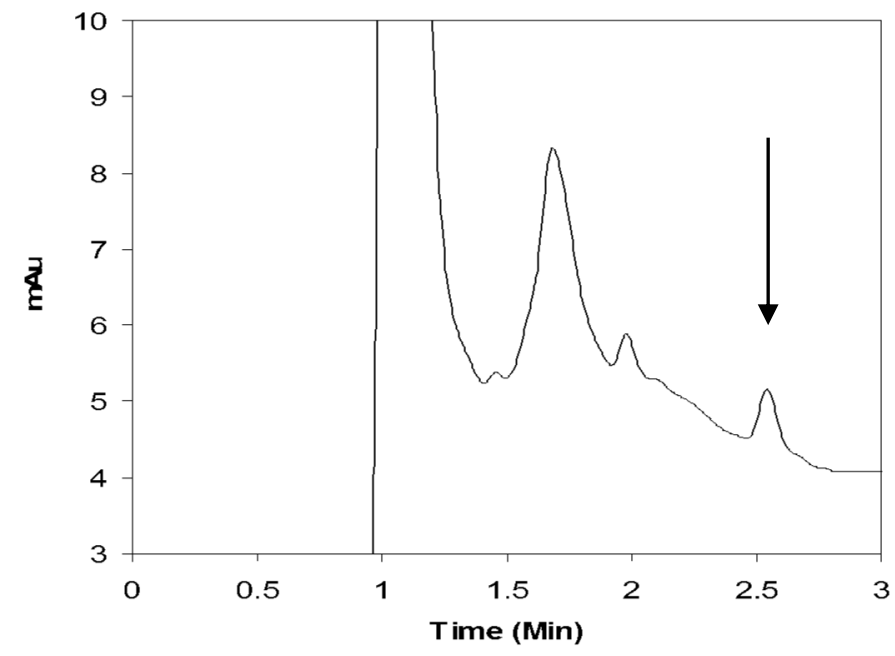

Figure 7. Chromatogram obtained from a $600 \mathrm{ngmL}^{-1}$ spiked ATC in rat plasma. ATC peak marked with arrow

\section{DISSCUSSION}

In the literature, the amorphous binary system of two drugs or a drug and a small molecule excipient are defined as coamorphous systems $(10,31)$. These systems show molecular interaction between two components (17) or without evidence of intermolecular interactions (13). In this investigation, ATC in the presence of NIC was completely converted to the coamorphous form, as it is evident from disappearance of typical pattern of ATC in PXRD and melting endotherm in DSC thermogram (32-33). For the spectral interpretation of the 1:1 molar ratio of ATC and NIC, it was important to compare the spectra with crystalline forms and those of the individual amorphous ATC as reported by Kim et al. (21). The crystalline form has sharper and significant peaks at $3666 \mathrm{~cm}^{-1}$ indicating free $\mathrm{O}-\mathrm{H}$ stretching while the ATC-NIC does not show any peaks in this region. The peaks in $3363(\mathrm{~N}-\mathrm{H}), 3056(\mathrm{O}-\mathrm{H}), 1243(\mathrm{C}-\mathrm{N}) \mathrm{cm}^{-1}$ were seen in the FT-IR spectra of crystalline ATC. These peaks were shifted to 3402,3058 and $1311 \mathrm{~cm}^{-1}$ in the ATC-NIC coamorphous form. These results are in agreement with FT-IR spectra of crystalline and amorphous form reported by Kim and coworkers (20). 
Table 2. Results of concentration accuracy in blank rat plasma samples in three different concentrations

\begin{tabular}{lll}
\hline Amount Added $\left(\mathrm{ngmL}^{-1}\right)$ & Concentration found $\left(\mathrm{ngmL}^{-1}\right)$ & Accuracy $(\%)$ \\
\hline 0.20 & $0.21 \pm 0.04$ & 110.0 \\
1.20 & $1.14 \pm 0.14$ & 99.2 \\
3.00 & $2.99 \pm 0.13$ & 99.6 \\
\hline
\end{tabular}

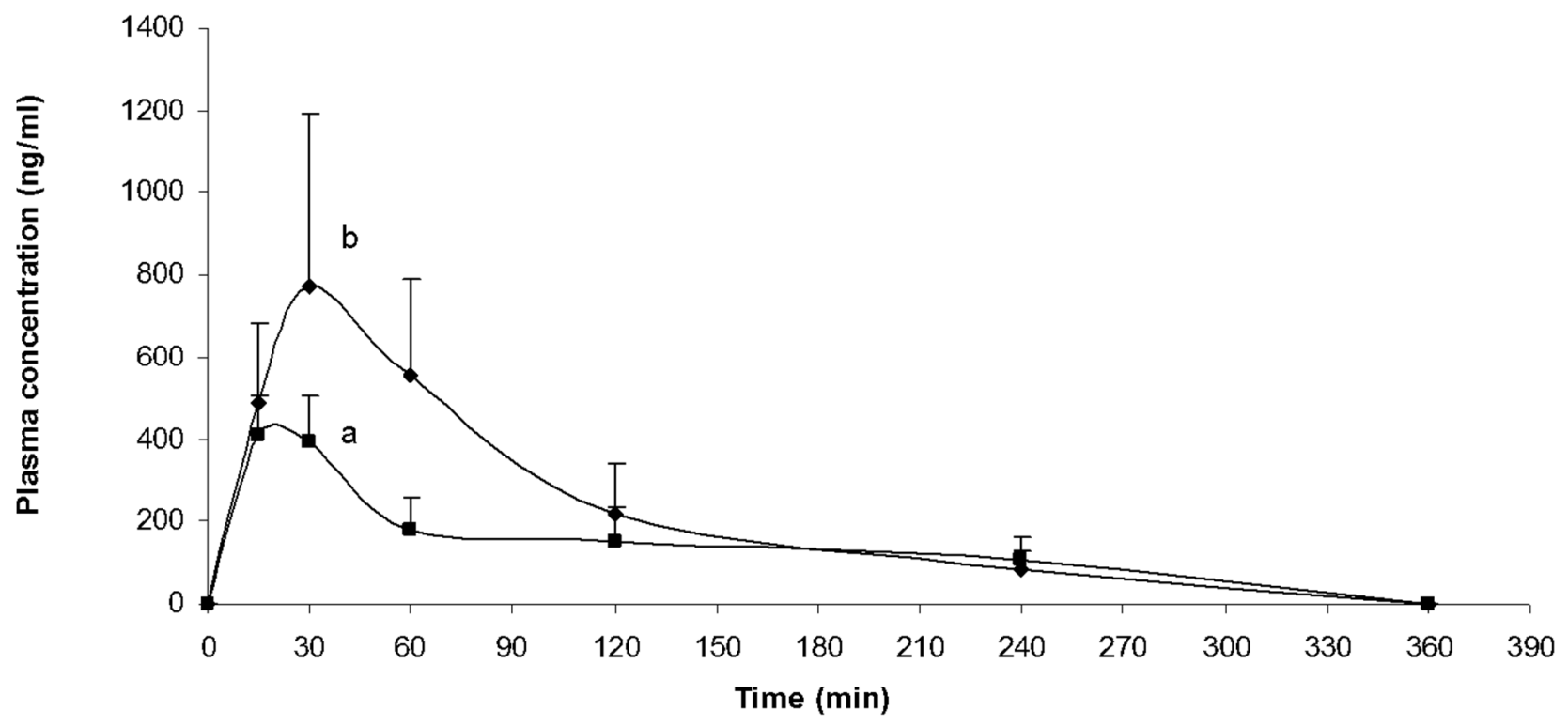

Figure 8. Plasma concentration-time curves of ATC (a) and ATC-NIC after oral administration of $25 \mathrm{mgkg}^{-1} \mathrm{dose}^{\text {. Error }}$ bars show standard error of the mean.

There is a significant difference between carbonyl stretching bond of crystalline ATC $\left(1649 \mathrm{~cm}^{-1}\right)$, amorphous ATC $\left(1662 \mathrm{~cm}^{-1}\right)$ in the literature (20), and ATC-NIC $\left(1670 \mathrm{~cm}^{-1}\right)$. This slight shift can correspond to the carbonyl group of ATC which is interacting via H-bonding with NIC. If ATC and NIC were not interacting on the molecular level no peak shifts should be detected for the corresponding peaks in amorphous form. Similar FT-IR pattern was observed for coamorphous drug systems of naproxen and indomethacin (17).

Unlike a crystalline drug, equilibrium solubility could not be determined for amorphous form of drugs, thus kinetic solubility was used to assess the coamorphous form (31). The kinetic solubility studies were performed to evaluate solution stability and the length of time for ATC to remain supersaturated prior to recrystallization $(20,31)$. The solubility data confirmed that coamorphous system resulted in enhanced solubility and stability under supersaturation conditions. This is simply known as spring and parachute concept (34), a phenomenon in which the metastable form maintains a high drug concentration for a long period of time.

Kim et al. reported amorphous ATC prepared using supercritical antisolvent and spray drying process, with maximum solubility after $20 \mathrm{~min}$ and then the solubility decreased. There is no significant difference between solubility of crystalline and amorphous of ATC after $24 \mathrm{hr}(20,21)$. This is unlike the amorphous form which shows maximum solubility but quickly fell as a result of crystallization in the dissolution studies (34). The results of our studies confirm that amorphous small molecule mixtures (coamorphous or amorphous cocrystals) can be used to produce amorphous forms with improved solution stability under supersaturated conditions. The results of this study in a good agreement with the results of Rades and coworkers $(9,35)$ and Gao et al. studies $(31)$. The mechanism of ATC solubility enhancement is as a result of converting crystalline ATC to coamorphous form. FTIR studies confirmed molecular interaction between ATC and NIC, thus in this example hydrotropy is not possible 
mechanism of improving ATC solubility. Further, hydrotropic effects occur in rather high solution concentrations. For example, the minimum concentration to improve solubility using NIC as hydrotrop agent is $2.5 \%$ for estrone and griseofulvin (36) and $4.9 \%$ for nimesulide (37) and $1.2 \%$ for riboflavin (38). In our study, kinetic solubility of ATC-NIC was conducted in the presence of $100 \mathrm{mg}$ ATC equivalent in water, thus the concentration of NIC in this solution was $0.01 \%$.

Thermodynamic analyses indicated that the solution process of $\Delta H_{d i s}$ and $\Delta S_{d i s}$, are positive and negative, respectively (unfavorable from enthalpic and entropic points), for both of ATC and ATCNIC. The main contributor to the standard free energy of solution process is entropy for ATC-NIC and crystalline ATC.

The coamorphous form of ATC-NIC was found to have higher powder and intrinsic dissolution rate compared to a physical mixture of ATC + NIC. This confirms that the enhanced dissolution rate was independent of the crystal habit or particle size (34). In addition, these studies indicated that in the physical mixture sample, NIC had no effect on the dissolution of ATC. This further confirmed that NIC was not acting like a hydrotrop.

The preliminary pharmacokinetic study with quantification of ATC concentration using modified a HPLC method showed oral absorption of ATCNIC is higher when compared to crystalline ATC. Increasing the dissolution rate and solubility of stable coamorphous form of ATC are the reasons of enhanced plasma concentration of ATC. Therefore, coamorphous drug system can be applied for improving solubility, dissolution rate and bioavailability of ATC.

Different methods were proposed to improve dissolution rate and pharmacokinetic properties of ATC such as solid dispersion technique (39), liquisolid compacts (40), nanosizing (41), lipid based formulations i.e. self-emulsifying drug delivery systems (42), complex formation with cyclodextrin (43) and preparation of amorphous atorvastatin using different methods $(20,21,32)$. The results of this study are in agreement with the previous studies and reveal that improving the dissolution rate can enhance pharmacokinetic properties of ATC, a well known fact for compounds categorized as BCS II.

\section{ACKNOWLEDGMENT}

This article is a part of the results of the $\mathrm{PhD}$ thesis No. 64 submitted to the Faculty of Pharmacy, Tabriz University of Medical Sciences, Tabriz, Iran. The authors would like to thank PXRD lab, Institute of Mineralogy, North Western Regional Office, Tabriz, Iran for providing PXRD patterns and biomedical analysis of Liver and Gastrointestinal Diseases Research Center, Tabriz University of Medical Sciences, Tabriz, Iran for bioanalysis equipments. We also thank Prof. Hadi Valizadeh and Rana Fazeli-Bakhtiyari for their helps in this study. Financial support by Faculty of Pharmacy, Tabriz University of Medical Sciences is acknowledged. We also appreciate Dr. Kia Sepassi, Johnson \& Johnson Pharmaceutical Research and Development, San Diego, CA, for proof reading of the manuscript and valuable comments.

\section{REFERENCES}

1. Williams HD, Trevaskis NL, Charman SA, Shanker RM, Charman WN, Pouton CW, Porter CJ. Strategies to address low drug solubility in discovery and development. Pharmacol Rev. 2013; 65:315-499.

2. Di L, Fish PV, Mano T. Bridging solubility between drug discovery and development. Drug Discov Today, 2012; 17:486-495.

3. Wu CY, Benet LZ. Predicting drug disposition via application of BCS: transport/absorption/elimination interplay and development of a biopharmaceutics drug disposition classification system. Pharm Res, 2005; 22:11-23.

4. Amidon GL, Lennernäs H, Shah VP, Crison JR. A theoretical basis for a biopharmaceutic drug classification: the correlation of in vitro drug product dissolution and in vivo bioavailability. Pharm Res, 1995; 12:413-420.

5. Kawakami K. Modification of physicochemical characteristics of active pharmaceutical ingredients and application of supersaturatable dosage forms for improving bioavailability of poorly absorbed drugs. Adv Drug Del Rev, 2012; 64:480-495.

6. Lu J, Rohani S. Polymorphism and crystallization of active pharmaceutical ingredients (APIs). Curr Med Chem, 2009; 16:884-905.

7. Blagden N, de Matas M, Gavan PT, York P. Crystal engineering of active pharmaceutical ingredients to improve solubility and dissolution rates. Adv Drug Del Rev, 2007; 59:617-630.

8. Schultheiss N, Newma A. Pharmaceutical cocrystals and their physicochemical properties. Cryst Growth Des, 2009; 9:2950-2967.

9. Sun Y, Zhu L, Wu T, Cai T, Gunn EM, Yu L. Stability of amorphous pharmaceutical solids: 
Crystal growth mechanisms and effect of polymer additives. AAPS J, 2012; 14:380-388.

10. Laitinen R, Löbmann K, Strachan CJ, Grohganz H, Rades T. Emerging trends in the stabilization of amorphous drugs. Int J Pharm, 2013; 453: 65-79.

11. Yamamura S, Gotoh H, Sakamoto Y, Momose Y. Physicochemical properties of amorphous precipitates of cimetidine-indomethacin binary system. Eur J Pharm Biopharm, 2000; 49:259-265.

12. Chieng N, Aaltonen J, Saville D, Rades T. Physical characterization and stability of amorphous indomethacin and ranitidine hydrochloride binary systems prepared by mechanical activation. Eur J Pharm Biopharm, 2009; 71:47-54.

13. Löbmann K, Strachan C, Grohganz H, Rades T, Korhonen O, Laitinen R. Co-amorphous simvastatin and glipizide combinations show improved physical stability without evidence of intermolecular interactions. Eur J Pharm Biopharm, 2012; 81: 159169.

14. Yamamura S, Gotoh H, Sakamoto Y, Momose Y. Physicochemical properties of amorphous salt of cimetidine and diflunisal system. Int J Pharm, 2002; 241:213-221.

15. Masuda T, Yoshihashi Y, Yonemochi E, Fujii K, Uekusa H, Terada K. Cocrystallization and amorphization induced by drug-excipient interaction improves the physical properties of acyclovir. Int $\mathbf{J}$ Pharm, 2011; 442:160-169

16. Allesø M, Chieng N, Rehder S, Rantanen J, Rades $\mathrm{T}$, Aaltonen J. Enhanced dissolution rate and synchronized release of drugs in binary systems through formulation: Amorphous naproxencimetidine mixtures prepared by mechanical activation. J Control Release, 2009; 136:45-53.

17. Löbmann K, Laitinen R, Grohganz H, Gordon KC, Strachan C, Rades T. Coamorphous drug systems: enhanced physical stability and dissolution rate of indomethacin and naproxen. Mol Pharm, 2011; 8:1919-1928.

18. Tiwari R, Pathak K. Statins therapy: a review on conventional and novel formulation approaches. J Pharm Pharmacol, 2011; 63:983-998.

19. Sonje V.M., Kumar L., Meena C.L., Kohli G., Puri V., Jain R., Bansal A.K. Brittain H.G., in: Harry GB (eds.), Profiles of Drug Substances, Excipients and Related Methodology, Academic Press, Waltham, Massachusetts, pp 1-70, 2010.

20. Kim MS, Jin SJ, Kim JS, Park HJ, Song HS, Neubert RHH, Hwang SJ. Preparation, characterization and in vivo evaluation of amorphous atorvastatin calcium nanoparticles using supercritical antisolvent (SAS) process. Eur J Pharm Biopharm, 2008; 69:454-465.

21. Kim JS, Kim MS, Park HJ, Jin SJ, Lee S, Hwang SJ. Physicochemical properties and oral bioavailability of amorphous atorvastatin hemi-calcium using spray-drying and SAS process. Int J Pharm, 2008; 359:211-219.

22. V.A.P. Vasantray, Doshi Vinay, EP 2075246 A1, 2009.

23. Y. Kumar;, R.K. Thaper and S.M.D. Kumar, US 2003/0149279, 2003.

24. Wouters, J., Sandrine R., Quere L., in: Wouters J, Quere L (eds.) Pharmaceutical Salts and Co-crystals, Vol 16, Royal Society of Chemistry, London, pp 338-382, 2011.

25. Panahi-Azar V, Shayanfar A, Martínez F, Acree Jr WE, Jouyban A. Thermodynamic studies of fluphenazine decanoate solubility in propylene glycol+water mixtures and correlation with the Jouyban-Acree model. Fluid Phase Equilib, 2011; 308:72-77.

26. Zakeri-Milani P, Barzegar-Jalali M, Azimi M, Valizadeh H. Biopharmaceutical classification of drugs using intrinsic dissolution rate (IDR) and rat intestinal permeability. Eur J Pharm Biopharm, 2009; 73:102-106.

27. Rahman Z, Agarabi C, Zidan AS, Khan SR, Khan MA. Physico-mechanical and stability evaluation of carbamazepine cocrystal with nicotinamide. AAPS PharmSciTech, 2011; 12:693-704.

28. Novakova L, Šatínský D, Solich P. HPLC methods for the determination of simvastatin and atorvastatin. Trends Anal Chem, 2008; 27:352-367.

29. Altuntas T, Erk N. Liquid chromatographic determination of atorvastatin in bulk drug, tablets, and human plasma. J Liq Chromatogr Rel Technol, 2004; 27:83-93.

30. Bansal S, DeStefano A. Key elements of bioanalytical method validation for small molecules. AAPS J, 2007; 9:109-114.

31. Gao Y, Liao J, Qi X, Zhang J. Coamorphous repaglinide-saccharin with enhanced dissolution. Int J Pharm, 2013; 450: 290-295.

32. Zhang HX, Wang JX, Zhang ZB, Le Y, Shen ZG, Chen JF. Micronization of atorvastatin calcium by antisolvent precipitation process. Int J Pharm, 2009; 374:106-113.

33. Shah, N., Sandhu H., Choi D.S., Kalb O., Page S. Wyttenbach N., in: Williams III RO: Watts AB: Miller DA (eds.), Formulating Poorly Water Soluble Drugs, Springer, New York, pp 267-310, 2011.

34. Babu NJ, Nangia A. Solubility advantage of amorphous drugs and pharmaceutical cocrystals. Cryst Growth Des, 2011; 11:2662-2679.

35. Löbmann K, Grohganz H, Laitinen R, Strachan C, Rades T. Amino acids as co-amorphous stabilizers for poorly water soluble drugs - Part 1: Preparation, stability and dissolution enhancement. Eur J Pharm Biopharm. 2013; doi: http://dx.doi.org/10.1016/j.ejpb.2013.03.014.

36. Sanghvi R, Evans D, Yalkowsky SH. Stacking complexation by nicotinamide: A useful way of 
enhancing drug solubility. Int J Pharm. 2007;336:3541.

37. Agrawal S, Pancholi SS, Jain NK, Agrawal GP. Hydrotropic solubilization of nimesulide for parenteral administration. Int $\mathrm{J}$ Pharm. 2004;274:149-55.

38. Coffman RE, Kildsig DO. Effect of nicotinamide and urea on the solubility of riboflavin in various solvents. J Pharm Sci. 1996;85:951-4.

39. Maurya D, Belgamwar V, Tekade A. Microwave induced solubility enhancement of poorly water soluble atorvastatin calcium. J Pharm Pharmacol, 2010; 62:1599-1606.

40. Gubbi SR, Jarag R. Formulation and characterization of atorvastatin calcium liquisolid compacts. Asian J Pharm Sci, 2010; 5:50-60.
41. Anwar M, Warsi MH, Mallick N, Akhter S, Gahoi S, Jain GK, Talegaonkar S, Ahmad FJ, Khar RK. Enhanced bioavailability of nano-sized chitosanatorvastatin conjugate after oral administration to rats. Eur J Pharm Sci, 201; 44:241-249.

42. Shen HR, Zhong MK. Preparation and evaluation of self-microemulsifying drug delivery systems (SMEDDS) containing atorvastatin. J Pharm Pharmacol, 2006; 58:1183-1191.

43. Palem CR, Patel S, Pokharkar VB. Solubility and stability enhancement of atorvastatin by cyclodextrin complexation. PDA J Pharm Sci Technol, 2009; 63:217-225. 